\title{
Multicyclic conversion of limestone at Ca-looping conditions: The role of solid-sate diffusion controlled carbonation
}

Pedro E. Sanchez-Jimenez ${ }^{a}$, Jose M. Valverde ${ }^{b}$, Luis A. Perez-Maqueda ${ }^{a}$

${ }^{a}$ Instituto de Ciencia de Materiales de Sevilla, Americo Vespucio 49, 41092 Sevilla, Spain

${ }^{b}$ Faculty of Physics. University of Seville. Avenida Reina Mercedes s/n, 41012 Sevilla, Spain 


\begin{abstract}
Limestone derived $\mathrm{CaO}$ conversion when subjected to multiple carbonation/calcination cycles is a subject of interest currently fueled by several industrial applications of the so-called Ca-looping (CaL) technology. The multicyclic $\mathrm{CaO}$ conversion at Ca-looping conditions exhibits two main features as demonstrated by thermogravimetric analysis (TGA). On one hand, carbonation occurs by two well differentiated phases: a first kinetically-driven fast phase and a subsequent much slower solid-state diffusion controlled phase. On the other, carbonation in the fast phase usually exhibits a drastic decay with the cycle number along the first carbonation/calcination cycles. This trend can be reversed by means of heat pretreatment, which induces a marked loss of fast conversion in the first carbonation but enhances diffusion of $\mathrm{CO}_{2}$ in the solid. Upon decarbonation the regenerated $\mathrm{CaO}$ skeleton shows an increased conversion in the fast carbonation phase of the next cycle, a phenomenon which has been referred to as reactivation. Nonetheless, sorbent reactivation is hampered by looping carbonation/calcination conditions as those to be likely found in practice such as carbonation stages characterized by low $\mathrm{CO}_{2}$ concentrations and short duration and calcination stages at high temperatures in a $\mathrm{CO}_{2}$ enriched atmosphere, which causes a sintering and loss of activity of the regenerated $\mathrm{CaO}$ skeleton. We analyze in this work sorbent reactivation as affected by heat pretreatment and carbonation/calcination conditions. Aimed at shedding light on the role played by these conditions on reactivation we look separately at the multicyclic evolution of conversion in the kinetic and diffusive phases. Generally, the evolution of multicyclic conversion after the first cycle can be described by a balance between the surface area gain due to diffusive carbonation and the surface area loss as caused by sintering in the calcination stage. A significant gain of relative surface area after the first cycle, which is favored by harshening the heat pretreatment conditions, leads however to a marked decay of it during subsequent cycles, which precludes reactivation for an extended interval of cycles. On the other hand, sorbent grinding, if performed before heat pretreatment, leads to a less marked but more sustainable reactivation along the cycles. A novel observation reported in our work is that pretreatment of limestone in a $\mathrm{CO}_{2}$ atmosphere leads upon a subsequent quick decarbonation to a $\mathrm{CaO}$ skeleton with extraordinarily enhanced reactivity in the kinetically-driven carbonation phase and with a high resistance to solid-state diffusion, which can be attributed to annealing of the crystal structure as reported by independent studies.
\end{abstract}




\section{INTRODUCTION}

The Calcium-looping (CaL) technology, based on the carbonation reaction of $\mathrm{CaO}$ at high temperature followed by calcination of $\mathrm{CaCO}_{3}$ to regenerate the sorbent $[1,2]$, is a current subject of intense research with promising applications on diverse industrial processes such as post-combustion $\mathrm{CO}_{2}$ capture [3], enhancement of the steam methane reforming (SE-SMR) via pre-combustion $\mathrm{CO}_{2}$ capture [4] and storage of thermal energy [5, 6]. Large pilot-scale plants $\left(\sim 1 \mathrm{MW}_{t}\right)$ have already demonstrated post-combustion $\mathrm{CO}_{2}$ capture efficiencies over $90 \%$, which raises hopes of scaling the technology up to a commercial level in the short-term [3]. As regards pre-combustion $\mathrm{CO}_{2}$ capture applications, higher methane to hydrogen conversion and improved energy efficiency are achieved by on-line capture of $\mathrm{CO}_{2}$ while steam methane reforming and water gas shift reactions are taking place [4, 7]. Commercially available gasification technologies can be satisfactorily integrated with the $\mathrm{CO}_{2}$ sorption-enhanced water gas shift process for advanced coal-based power plants [8]. Recently, a concentrated solar power (CSP) plant concept has been proposed which uses the CaL technology for heat transport and storage [6]. Concentrated solar energy is applied to the calciner providing the energy required for decarbonation whereas energy is released and transferred into the carrying air to a gas turbine from the exothermic carbonation between $\mathrm{CaO}$ and the stored $\mathrm{CO}_{2}$.

While optimal material properties and reactor conditions for SE-SMR and CaL-CSP industrial plants are still a subject of debate $[4,6]$, CaL conditions for $\mathrm{CO}_{2}$ post-combustion capture seem to be well defined $[2,9]$. In the practical application, $\mathrm{CaO}$ particles must react in a fluidized bed reactor (carbonator) with $\mathrm{CO}_{2}$ present at low concentrations (around 15\% vol) in the inlet stream of flue gas, which flows at velocities of a few $\mathrm{m} / \mathrm{s}$. Partially carbonated particles are circulated into a second fluidized bed reactor (calciner) where a pure stream of $\mathrm{CO}_{2}$ ready for transport and storage is produced and the sorbent is regenerated for its re-use in a new cycle. By taking into account the tradeoff between the reaction equilibrium driving force at atmospheric pressure and the reaction kinetics, the optimal carbonation temperature is around $650^{\circ} \mathrm{C}$ whereas calcination must be carried out at temperatures of about $900^{\circ} \mathrm{C}$ to ensure decarbonation in the $\mathrm{CO}_{2}$ rich atmosphere of the calciner.

Thermogravimetric analysis (TGA) tests demonstrate that carbonation of $\mathrm{CaO}$ proceeds along two well differentiated phases. A first kinetically-driven fast reaction phase occurring 
at the surface of the particles is followed by a much slower carbonation controlled by diffusion of $\mathrm{CO}_{2}$ in the solid $[10,11]$, which is determined by the counter-current diffusion of inward $\mathrm{CO}_{3}^{2-}$ anion groups and outward $\mathrm{O}^{2-}$ anions $[12,13]$. Fast conversion (of interest in practice $[10,11])$ suffers a progressive decay with the cycle number as due to sintering of nascent $\mathrm{CaO}$ in the calcination stage, which represents a drawback for the efficiency of the CaL technology. Achieving the goal of sustained post-combustion $\mathrm{CO}_{2}$ capture efficiencies requires thus a periodical purging of the low-conversion spent sorbent and high solids recirculation rates to counteract the loss of $\mathrm{CaO}$ conversion in the fast phase, which is further demanded by irreversible $\mathrm{CaO}$ sulphation due to the presence of $\mathrm{SO}_{2}$ in the flue gas. This brings about significant operating challenges to the plant whereas an excessive amount of fresh makeup limestone hampers the thermal efficiency of the process [9]. Under these circumstances, the industrial competitiveness of the technology is currently guaranteed only if a cheap and widely available $\mathrm{CaO}$ precursor, such as natural limestone, is used $[2,14]$.

Enhancing the conversion stability of CaO-based sorbents at low cost is a challenge to improve the efficiency of the CaL technology $[6,15]$. Current directions of research aimed at this goal are the modification/synthesis of Ca-based sorbents $[16,17]$ and reactivation of natural limestone either by steam $[18,19]$ or heat pretreatment [20-28]. Lysikov et al. [20] and Manovic and Anthony [21] observed that the exposition of limestone to isothermal heating at high temperature for a prolonged period of time (heat pretreatment) yielded a $\mathrm{CaO}$ skeleton whose conversion in multicyclic TGA tests increased with the cycle number. Sorbent reactivation by heat pretreatment depends on a variety of experimental conditions such as temperature and duration of the pretreatment, presence of additives/impurities, pre-grinding, pre-hydration and subsequent looping carbonation/calcination conditions. A common qualitative observation is that reactivation is essentially caused by the enhancement of carbonation of the pretreated sorbent in the solid-state diffusion phase, which would lead upon decarbonation to a $\mathrm{CaO}$ skeleton with increased activity. Nonetheless, the multicyclic conversion of pretreated limestones exhibiting reactivation has been tested in most of previous studies by means of carbonation/calcination cycles carried out isothermally (at temperatures in the range $750-850^{\circ} \mathrm{C}$ ) whereas the gas is switched between an inert gas for calcination and a mixture with high $\mathrm{CO}_{2}$ vol\% for carbonation (usually above 25\%) [20-24, 26, 27]. Under these looping carbonation/calcination conditions, carbonation in the solid-state diffusion controlled phase would be favored while significant sintering of the 
nascent $\mathrm{CaO}$ upon decarbonation in the calcination stage is minimized. Sorbent reactivation is not seen in tests carried out under more realistic carbonation/calcination conditions implying lower $\mathrm{CO}_{2}$ vol\% during carbonation and calcination temperatures above $850^{\circ} \mathrm{C}$ that intensify sintering of the nascent $\mathrm{CaO}[28,29]$. In this manuscript we look in close detail to the role of diffusive carbonation on reactivation of a natural limestone subjected to a variety of pretreatment and carbonation/calcination conditions. An approach adopted in our study is to analyze the evolution of multicyclic conversion in the fast and diffusive phases separately, which is useful to further understand the mechanism that governs reactivation as well as to quantify it from a simple analytical model.

\section{MATERIALS AND METHODS}

High purity natural limestone supplied to us by Segura S.L. (Matagallar quarry in Pedrera, Spain) has been used as $\mathrm{CaO}$ precursor $\left(99.62 \% \mathrm{CaCO}_{3}, \mathrm{SiO}_{2}<0.05 \%, \mathrm{Al}_{2} \mathrm{O}_{3}<\right.$ $0.05 \%, 0.24 \% \mathrm{MgO}, 0.08 \% \mathrm{Na}_{2} \mathrm{O}$ ). In multicyclic carbonation/calcination tests we have used a Q5000IR TG analyzer (TA Instruments) provided with an infrared furnace heated by halogen lamps, which allows for a very fast change of temperature between cycles, and with a high sensitivity balance $(<0.1 \mu \mathrm{g})$ characterized by a minimum baseline dynamic drift $(<10 \mu \mathrm{g})$. The use of an infrared halogen furnace allowed us for heating/cooling the sample very quickly $\left(300^{\circ} \mathrm{C} \mathrm{min}^{-1}\right)$, which serves to minimize the duration of the transitional periods thus allowing to test the multicyclic conversion of the sorbent at conditions close to Ca-looping conditions in practice. As a general procedure in the TGA multicyclic tests, a sample of the sorbent (mass around $10 \mathrm{mg}$ ) was firstly subjected in-situ to a linear heating program $\left(20^{\circ} / \mathrm{min}\right)$ up to $850^{\circ} \mathrm{C}$ in dry air prior to the carbonation/calcination cycles. Benchmark conditions of subsequent carbonation/calcination cycles consisted of carbonation at $650^{\circ} \mathrm{C}\left(85 \%\right.$ dry air $\left./ 15 \% \mathrm{CO}_{2} \mathrm{vol} / \mathrm{vol}\right)$ and calcination at $850^{\circ} \mathrm{C}$ (dry air), both stages for 5 minutes. Additional tests were performed at diverse carbonation conditions (prolonging the carbonation period to $30 \mathrm{~min}$ and increasing the $\mathrm{CO}_{2}$ vol\% up to 50\%) and at lower calcination temperature $\left(750^{\circ} \mathrm{C}\right)$.

Before carrying out the multicyclic carbonation/calcination tests, the material could be subjected to diverse types of pretreatment such as grinding and prolonged isothermal heating in a separate oven (at temperatures of $850^{\circ} \mathrm{C}$ and $950^{\circ} \mathrm{C}$ for $12 \mathrm{~h}$ ) in either dry air or pure 
$\mathrm{CO}_{2}$ atmospheres. Grinding was carried out as follows: $6.5 \mathrm{~g}$ of material was placed in a $100 \mathrm{~cm}^{3}$ steel jar with 200 tungsten carbide balls $(5.5 \mathrm{~mm}$ in diameter) as grinding media. Limestone-to-ball mass ratio was set at 1:40. Milling of the mixture was performed in a centrifugal ball-mill (Fritsch Pulverisette 6, centrifugal version, Idar-Oberstein, Germany) at $500 \mathrm{rpm}$ for 1 hour. In order to avoid the effect of diffusion resistance through the pore network inside the particles on the reaction rate, which might be relevant for particles typically larger than $300 \mu \mathrm{m}$ as reported elsewhere [11], we have carried out our study using a small particle size limestone (volume weighted mean $9.5 \mu \mathrm{m}$ ). Thus, even though grinding might lead to a further decrease of particle size, the influence of $\mathrm{CO}_{2}$ diffusion effects inside the particles on the reaction rate may be disregarded $[11,12]$. The effect of pretreatment on the sorbent pore size distribution (BJH method) was further investigated by means of a TriStar II 3020 V1.03 physisorption analyzer operated by $\mathrm{N}_{2}$ sorption at $77 \mathrm{~K}$.

\section{EXPERIMENTAL RESULTS AND DISCUSSION}

\section{A. Effect of pregrinding}

Figure 1a shows the evolution of sample weight $\%$ obtained from the multicyclic TG tests as a function of time during the first 3 carbonation/calcination cycles for raw and preground limestone (not subjected to heat pretreatment). A fast (kinetically controlled) carbonation phase is clearly distinguishable from a subsequent much slower (solid-state diffusion controlled) phase by a marked change of the rate of weight $\%$ gain, which serves us to infer the values of conversion separately in both phases. Conversion in the kinetically controlled phase $\left(X_{K N}\right)$ and diffusive phase $\left(X_{D N}\right)$ are plotted in Fig. 1b as a function of

the cycle number $N$. It can be observed that $X_{K N}$ is not essentially affected by pregrinding whereas, on the other hand, pregrinding significantly enhances diffusive carbonation $X_{D N}$ by a factor which is independent of the cycle number. Local high stresses provoked by grinding exceed the forces of cohesion between the lattice atoms, which gives rise to crystal cracking and promotes structural defects that would facilitate $\mathrm{CO}_{2}$ diffusion through the solid [30]. A common feature of the multicyclic conversion observed for both sorbents is the rapid decrease of fast conversion with the cycle number as generally observed for natural nonpretreated limestones [31]. On the other hand, diffusive conversion increases in the first 3-4 cycles after 
which it decreases at a slow rate with the cycle number. As a result, the ratio $X_{D N} / X_{K N}$ (plotted in the inset of Fig. 1b) turns to be an increasing function of the cycle number. In any case, this ratio remains small. $\mathrm{CaO}$ conversion in the carbonation/calcination conditions employed in our test is seen to be mostly due to fast carbonation for these non thermally pretreated sorbents.

\section{B. Effect of heat pretreatment}

A general result reported in the literature is that preheating limestones for a prolonged time period at high temperatures gives rise to a very sintered $\mathrm{CaO}$ skeleton [21-23], which hampers conversion in the first cycle. The effect of heat pretreatment observed in our tests in agreement with this general result is illustrated in Fig. 2. Figure 2a demonstrates that the harsher the pretreatment conditions the smaller is conversion in the fast phase of the first cycle. On the other hand, the ratio of diffusive conversion to fast conversion $X_{D N} / X_{K N}$ in the first cycle is enhanced by increasing the pretreatment temperature (inset of Fig. 2b). In the 2nd cycle, conversion in the fast phase is increased (Fig. 2b) but both fast and slow conversion decay afterwards at a small rate with the cycle number. Interestingly, the trend of the ratio $X_{D N} / X_{K N}$ in the first cycles (inset of Fig. 2b) is reversed as compared with the trend observed for the sorbents which were not thermally pretreated (inset of Fig. 1b).

As suggested by previous works [32], heat pretreatment promotes $\mathrm{CO}_{2}$ diffusion in the solid during the 1st carbonation stage, which yields a regenerated $\mathrm{CaO}$ skeleton after decarbonation with an increased activity in the 2nd cycle. Pore size distributions of thermally pretreated limestones reported by Manovic et al. [23] show accordingly a notable increase of the population of pores of size $<100 \mathrm{~nm}$ when deeply sintered pretreated samples were subjected in a tube furnace to carbonation/calcination cycles during which reactivation was observed. Thus, even though the mass of the sorbent tested in multicyclic TGA experiments is not sufficiently high as to carry out a physisorption analysis on the cycled samples, it is conceivable that the observed increase of conversion in the fast phase stems from the increase of surface area of the regenerated $\mathrm{CaO}$ skeleton after solid-state diffusion promoted by heat pretreatment. The increase of fast conversion with the cycle number would thus lead to a decrease of the ratio $X_{D N} / X_{K N}$ as seen in Fig. 2b (inset) for the first cycles. Yet, the looping-calcination temperature employed in our test is high enough as to induce a 
considerable sintering of the regenerated $\mathrm{CaO}$ skeleton, which precludes reactivation for an extended number of cycles. Consequently, both fast and diffusive conversion decrease at a slow rate for $N>2$ while the ratio $X_{D N} / X_{K N}$ reaches a stationary value around one. Note that, in contrast with the case of nonpretreated samples, diffusive carbonation is in this case similar to fast conversion.

A common observation reported in previous works [20-24, 26, 27] is that grinding prior to heat pretreatment favors reactivation. This is not the case however under the benchmark carbonation/calcination conditions employed in our tests. Figure $2 \mathrm{~b}$ shows instead relatively smaller values of conversion for the preground sorbent. Reactivation is neither observed under the conditions of our tests when the limestone is pretreated at a higher temperature $\left(950^{\circ} \mathrm{C}\right.$ as compared with $\left.850^{\circ} \mathrm{C}\right)$, which just serves to reduce conversion in both fast and slow phases to very small values (Fig. $2 \mathrm{~b}$ ). On the other hand, the activity of the sorbent pretreated at $950^{\circ} \mathrm{C}$ for $12 \mathrm{~h}$ is improved when it is ground after preheating. This is shown in Fig. 3 illustrating that, even though the ground sorbent after preheating recovers a relatively

high value of fast conversion, the conversion stability provided by thermal pretreatment is lost. Thus, conversion turns again to decay with the cycle number at a rate similar to the rate of conversion decay that was exhibited by the nonpretreated sorbent even though the values of conversion are clearly smaller.

\section{Effect of looping carbonation conditions}

Previous studies [22] have demonstrated that reactivation of thermally pretreated limestones is promoted by increasing either the $\mathrm{CO}_{2}$ vol\% or the time period in the carbonation stage of the cycles. Likewise, the fast conversion of limestones and dolomites was observed to be significantly enhanced if the sorbent was subjected to a prolonged carbonation period (of the order of hours) even after the sorbent had been subjected to a large number of carbonation/calcination cycles [20,33]. Diffusive carbonation is promoted during a long carbonation period under a $\mathrm{CO}_{2}$ rich atmosphere. Accordingly, the $\mathrm{CaO}$ skeleton upon decarbonation would become highly active (provided that calcination is not carried out under harsh conditions that might provoke substantial sintering of the nascent $\mathrm{CaO}$ ). Results obtained in our work when the $\mathrm{CO}_{2}$ vol\% during carbonation was increased up to $50 \%$ and the carbonation time was prolonged up to 30 min are shown in Fig. 4. As expected, reactivation 
becomes more apparent in these favorable conditions (inset of Fig. 4). A remarkable observation is that grinding prior to thermal pretreatment slows down the decay rate of diffusive carbonation with the cycle number and yields a steady increase of fast conversion. On the other hand, the pretreated sorbent which was not subjected to previous grinding exhibits a marked reactivation in the second cycle which is not sustained in the subsequent ones. As far as the overall conversion at the end of the carbonation phase $\left(X_{N}=X_{K N}+X_{D N}\right)$ is concerned, Fig. 5 shows that $X_{N}$ in increased with $N$ only if pregrinding is performed as usually reported elsewhere [21-23]. Thus, the failure to observe reactivation of thermally pretreated sorbents not subjected to previous grinding may be attributed on one hand to the evaluation of conversion in these studies as the sum of both fast and slow conversion and, on the other, to the rapid decrease of conversion in the diffusive phase with the cycle number in the case of non-preground sorbents.

\section{Pretreatment of $\mathrm{CaCO}_{3}$ in a $\mathrm{CO}_{2}$ atmosphere}

Lattice diffusion leading to a loss of surface area by sintering during heat pretreatment becomes rather significant as the temperature approaches the Tamman temperature (around $1 / 2$ the melting-point temperature in degrees $\mathrm{K}$ [34]), which is $1154^{\circ} \mathrm{C}$ for $\mathrm{CaO}$ and only $533^{\circ} \mathrm{C}$ for $\mathrm{CaCO}_{3}$. Thus, one might wonder whether pretreatment of limestone under $\mathrm{CO}_{2}$ at a temperature below $900^{\circ} \mathrm{C}$ (to avoid decomposition), which would cause a marked sintering of $\mathrm{CaCO}_{3}$, might have an appreciable effect on the multicyclic conversion of the $\mathrm{CaO}$ later derived upon rapid decarbonation. Figure 6, illustrating the multicyclic thermograms obtained for a sample of limestone pretreated in this way $\left(12 \mathrm{~h}\right.$ at $850^{\circ} \mathrm{C}$ under a pure $\mathrm{CO}_{2}$ atmosphere), shows otherwise. The $\mathrm{CO}_{2}$-pretreated limestone sample exhibits an almost identical multicyclic performance to the nonpretreated limestone. It is remarkable though that the 1st carbonation of the $\mathrm{CO}_{2}$-pretreated sample occurs by means of a very quick fast carbonation phase whereas there is almost no carbonation in the diffusive phase (see Fig. $6 \mathrm{~b}$ and the inset showing an increase of the reaction rate in the kinetically-controlled fast phase by a factor larger than 3). Note that the behavior of the $\mathrm{CO}_{2}$-pretreated sorbent in the second cycle recovers similar features to that of nonpretreated limestone as might have been expected since the $\mathrm{CaO}$ skeleton carbonated in this 2 nd cycle is originated from the $\mathrm{CaCO}_{3}$ lattice built up in the 1st carbonation (nonpretreated). On the other hand, 
the extraordinarily high reactivity of the 1st cycle is lost and diffusive carbonation becomes again appreciable if the sorbent is preground before $\mathrm{CO}_{2}$ thermal pretreatment (see Fig. 6b), which could be attributed to irreversible lattice damage induced by previous grinding.

\section{E. Physisorption analysis}

Pore size distributions and BET surface area of diverse samples are shown in Fig. 7. As commonly observed for natural limestones, the raw limestone used in our work is a material with a low porosity and a small surface area (below the experimental accuracy of the technique). As seen also in Fig. 7, grinding of the raw limestone causes an increase of the number of pores in the whole size range and a slight increase of the surface area. However, decarbonated samples $\left(850^{\circ} \mathrm{C}\right.$ for $30 \mathrm{~min}$ in air) of both raw and ground limestone show similar pore size distributions with a BET surface area of around $6 \mathrm{~m}^{2} / \mathrm{g}$ in both cases. This would explain their similar multicyclic behavior of fast conversion exhibited by either raw or ground samples (Fig. 1). As firstly observed by Barker [10], the decomposition of limestone into $\mathrm{CaO}$ generally results in a bimodal distribution of pore size with two main peaks centered around $\sim 20-80 \mathrm{~nm}$ and $\sim 2-4 \mathrm{~nm}$, the latter population caused by $\mathrm{CO}_{2}$ leaving the $\mathrm{CaCO}_{3}$ inward skeleton, which results in an open structured $\mathrm{CaO}$ skeleton with a high reactivity. These two peaks are also observed in the pore size distributions obtained for some of the samples in our study (Fig. 7). Note that the type of pretreatment affects the relative weight of both pore size populations. A prolonged heat treatment at high temperature $\left(950{ }^{\circ} \mathrm{C}\right.$ for $12 \mathrm{~h}$ in air) yields a decrease of the small pore population while the number of large pores is significantly enhanced. This would explain the low reactivity of this preheated sample in the fast carbonation phase. As firstly noted by Bhatia and Pelmutter [12], a substantially lower reaction rate in the kinetically driven phase is attributable to an increase of pore size. A similar reduction of microporosity accompanied by a parallel increase of mesoporosity was inferred elsewhere [35] from a SEM analysis of nonpretreated limestone samples as they were subjected to an increasing number of carbonation/calcination cycles and conversion converged towards a residual stable value. The efficiency of pretreatment on inducing small sorbent reactivity but high conversion stability seems thus to be related to the depletion of the less stable micropores. As regards the role of grinding before heat treatment, it is seen that it leads to a depletion of the population of small pores whereas 
the large pore population is enlarged (see Fig. 7). Accordingly, stability of the pretreated sorbent conversion is seen in our work and in previous studies [21] to be enhanced if the sorbent is preground before heat pretreatment. On the other hand, the pore size distribution obtained for the $\mathrm{CaO}$ skeleton resulting from the $\mathrm{CO}_{2}$ preheated limestone (at $850^{\circ} \mathrm{C}$ ) after rapid decarbonation $\left(850^{\circ} \mathrm{C}\right.$ for $30 \mathrm{~min}$ in air) shows a rise of the population of the small pores while the large pores peak is flattened even though there is not a marked increase of the BET surface area $\left(9.4 \mathrm{~m}^{2} / \mathrm{g}\right)$. This indicates that the rather high carbonation rate of the $\mathrm{CO}_{2}$-pretreated limestone in the fast phase of the first cycle (Fig. 6) would be due to a majority presence of small pores in the $\mathrm{CaO}$ skeleton resulting from a rapid decarbonation of the pretreated sample. Being its surface area close to that of $\mathrm{CaO}$ derived from raw limestone, conversions of both samples at the end of the fast phase are similar (Fig. 6). Nevertheless, it must be kept in mind that the $\mathrm{N}_{2}$ kinetic energy at $77 \mathrm{~K}$ to diffuse through small pores (of size close to the micropore region below $2 \mathrm{~nm}$ ) may not be large enough [36]. Using an alternative method with greater sensitiveness to small pores (such as $\mathrm{CO}_{2}$ adsorption at $273 \mathrm{~K}$ with higher diffusion rate) would be thus desirable as a complement to $\mathrm{N}_{2}$ adsorption at $77 \mathrm{~K}$ [37]. Note that if the limestone is heated in $\mathrm{CO}_{2}$ at $950^{\circ} \mathrm{C}$, which gives rise to decarbonation, the main peak in the pore distribution of the heated sample becomes again shifted in the large pore region since in this case $\mathrm{CaO}$ resulting from initial decomposition is sintered by the heat treatment (see Fig. 7). Preheating of limestone in $\mathrm{CO}_{2}$ at temperatures above $900^{\circ} \mathrm{C}$ causes accordingly a very low carbonation activity in the first cycle [23].

Concerning the effect of grinding of preheated samples, Fig. 7 shows also that grinding after heat pretreatment leads to a recovery of the population of small pores at expenses of a reduction of the large pore population. The pore size distribution obtained becomes then similar to those of the raw and preground limestones after quick decarbonation (non subjected to heat pretreatment). In accordance, it could be thought that the sorbent activity upon cycling will recover the same features to that of the nonpretreated decarbonated limestone. Yet, as seen in Fig. 3, the values of conversion of the ground limestone after heat pretreatment remain neatly below those corresponding to the nonpretreated limestone. This suggests that sorbent activity does not depend solely on the pore size distribution and surface area. A further evidence supporting this view may be retrieved from the very small values of initial conversion of limestones subjected to extremely harsh heat treatments 
reported by Manovic and Anthony [21] (as low as 0.01), which are well below the residual conversion of nonpretreated limestones already in a deeply sintered state $(0.07-0.08[31])$.

\section{F. Role of crystallinity on diffusive carbonation}

The enhancement of solid-state diffusive carbonation, as seen in our results when the sample is ground or preheated, would strongly depend on the effect of pretreatment on the crystal structure. Manovic and Anthony [21] suggested that heat pretreatment leads to the development of a hard $\mathrm{CaO}$ skeleton with a low resistance to solid-state diffusion. It might be argued that shear stresses generated during prolonged heating followed by rapid cooling deforms the $\mathrm{CaO}$ crystal structure by increasing the density of dislocations. Interference of dislocations with each other would serve to harden the solid (similarly to what happens in the well known process of metal hardening treatment by quenching) but dislocations would also offer short circuit paths of increased mobility for $\mathrm{CO}_{2}$ diffusion through the solid and facilitate $\mathrm{CaCO}_{3}$ nucleation [38]. This correlation between lattice structural defects and the carbonation rate in the solid-state diffusion controlled phase was already suggested by Bhattia and Pelmutter from experimental results on samples showing diverse degrees of structure crystallinity [12]. In our experiments, pregrinding would cause a permanent structural damage to the crystal structure that would enhance solid-state diffusivity for a large number of cycles as inferred from the response of the preground sorbent which was not subjected to heat pretreatment (Fig. 1). However, diffusive carbonation of the thermally pretreated sorbent in the 1st cycle is hindered by pregrinding (Fig. 4) whereas grinding after thermal pretreatment precludes reactivation (Fig. 3). This suggests that the effects caused on the crystal structure by both treatments (grinding and heat treatment) are interdependent. It could be possible that grinding, if carried out after heat treatment, leads to a decrease of the density of thermally induced dislocations while crystal imperfections caused by grinding on the nonpretreated sorbent affects the density of dislocations induced by thermal stresses in a subsequent heat pretreatment. As regards the strong resistance to solid-state diffusion exhibited by the $\mathrm{CO}_{2}$-pretreated limestone, it would be indicative of a scarce presence of crystal defects that would hinder $\mathrm{CO}_{2}$ diffusion in the solid. Indeed, heat pretreatment of limestone leads to annealing of the crystal structure as it has been investigated in detail by Liu et al. [39] who reported a considerable reduction in dislocation 
density of single-crystal calcites treated under a $\mathrm{CO}_{2}$ atmosphere. Annealing the crystal at $700^{\circ} \mathrm{C}$ for $24 \mathrm{~h}$ in $\mathrm{CO}_{2}$ yields a reduction of an order of magnitude in the diffusion coefficient of carbon in the calcite lattice as measured by Kronenberg et al. [40]. Likewise, Anderson [41] had previously reported a reduction by a factor of 50 of the self-diffusion coefficients of carbon and oxygen in calcite annealed at $750^{\circ} \mathrm{C}$ for two days under 0.2 atm $\mathrm{CO}_{2}$. These studies clearly show that the mechanism of solid-state diffusion is structure-sensitive. Since solid-state diffusion plays a relevant role on the structure of the regenerated $\mathrm{CaO}$ skeleton in multicyclic tests, a proper understanding of the multicyclic carbonation of Ca-based sorbents in the CaL process would be greatly benefitted from a detailed study on the effect of pretreatment history on the crystal structure.

\section{MULTICYCLIC CONVERSION MODELING}

Measurements of the surface area of nascent $\mathrm{CaO}$ samples subjected to isothermal heating reported elsewhere [42-45] suggest that the nascent $\mathrm{CaO}$ upon decomposition of $\mathrm{CaCO}_{3}$ forms an open packed array of spherical grains that interact by neck formation and neck growth at their points of contact resulting in a reduction of surface area from the transport

of matter by lattice diffusion. The dependence of the relative decrease of surface area $\frac{\Delta S}{S_{0}}$ with the sintering time $t_{s}$ measured in these studies conforms to the German-Munir equation

$$
\frac{\Delta S}{S_{0}}=\left(K_{s} t_{s}\right)^{1 / \gamma_{s}}
$$

for $\Delta S / S_{0}<0.5$. Here $S_{0}$ is the initial surface area and $K_{s}$ is the sintering rate constant. Under an inert dry atmosphere, the sintering rate of limestone derived $\mathrm{CaO}$ follows an Arrhenius type dependence with temperature taking typical values varying from $K_{s} \sim 10^{-4}$ $\min ^{-1}$ at $700^{\circ} \mathrm{C}$ to $K_{s} \sim 10^{-1} \mathrm{~min}^{-1}$ at $1100^{\circ} \mathrm{C}$. The exponent $\gamma_{s}$ has a value of $2.7 \pm 0.3$ independent of temperature and type of precursor in accordance with a lattice diffusion mechanism for sintering. Remarkably, $K_{s}$ is a function of the diffusion coefficient and surface tension being greatly increased by the presence of lattice defects [42-45]. In this regard it may be argued that grinding before thermal pretreatment serves to promote sintering of the $\mathrm{CaO}$ pore skeleton by accelerating lattice diffusion, thus causing a further decrease of microporosity as seen in Fig. 7.

As inferred from multicyclic $\mathrm{CaO}$ conversion results, a 1st diffusion enhanced carbonation 
would give rise upon decarbonation to a porous $\mathrm{CaO}$ skeleton with promoted surface area available for fast carbonation in the 2nd cycle. As long as diffusion controlled carbonation may proceed in subsequent cycles through the hard skeleton developed during pretreatment, fast conversion will be further enhanced. After a certain number of cycles (depending on the type of pretreatment) fast carbonation on the regenerated active skeleton takes over solidstate diffusion and surface area regeneration by this mechanism is precluded. Accordingly, the evolution of the active surface area with the carbonation/calcination cycle number $\left(S_{N}\right)$ can be described by the equation

$$
\frac{S_{N}}{S_{0}}=(1-a)^{N}(1+b)^{N^{\beta}}
$$

which has been derived elsewhere [46] from the balance between the surface area gain in each cycle due to diffusive carbonation and the surface area loss caused by sintering during calcination of the nascent $\mathrm{CaO}$ skeleton. Following the German-Munir model (Eq. 1), the relative loss of surface area in the calcination stage of the ith cycle is given by $S_{i+1} / S_{i}^{\prime}=1-a$, where $a$ is the so-called sintering factor, which may be related to the sintering rate $K_{s}$ and time period $t_{s}$ by $a=\left(K_{s} t_{s}\right)^{1 / \gamma_{s}}$. On the other hand, the relative gain of surface area due to diffusion in the carbonation stage of the ith cycle is proposed to scale as a power law equation $S_{i}^{\prime} / S_{i}=1+b(i+1)^{-q}$, where $b$ is the so-called regeneration factor and the sign of the exponent $q$ determines whether surface area relative gain increases with the cycle number $(q<0)$ due to the enhancement of the ratio of diffusive to fast carbonation (as would be the case of nonpretreated sorbents, Fig. 1b) or it decreases with the cycle number $(q>0)$ as would be the case of pretreated sorbents exhibiting reactivation for which the ratio of diffusive to fast carbonation decreases with the cycle number (Fig. 2b). Further elaboration of the model results in Eq. 2 where $\beta \simeq e^{-q}$. By assuming that fast conversion after the first cycle scales proportionally to the sorbent surface area, reactivation would occur for $b / a>1$ and $\beta<1$. Equation 2 predicts then a maximum value of the surface area at a cycle number $N_{\max }$ given by

$$
N_{\text {max }}=\left[\frac{\beta \log (1+b)}{-\log (1-a)}\right]^{1 /(1-\beta)}
$$

The value of $N_{\max }$ is increased as $\beta$ becomes closer to one, which would be the case in which the relative surface area gain associated to diffusive carbonation decreases at a slow rate 
with the cycle number. A prolonged reactivation behavior (as caused by pregrinding) is thus characterized by large values of $b / a$ and values of $\beta$ below but close to unity whereas small values of $\beta$ would yield a marked self-reactivation but just for a reduced number of cycles.

Experimental measurements [42] on the sintering of limestone derived $\mathrm{CaO}$ subjected to short-timed isothermal heating in a inert atmosphere yields $K_{s} \simeq 2 \times 10^{-3} \mathrm{~min}^{-1}$ at $850^{\circ} \mathrm{C}$, which allows us estimating $a \simeq 0.182$ in the looping-calcination conditions of our tests $\left(t_{s}=5\right.$ min). Presumably, decreasing the calcination temperature serves to boost reactivation as the sintering rate follows an Arrhenius type dependence with the temperature [42]. A $100^{\circ} \mathrm{C}$ decrease of the calcination temperature from $850^{\circ} \mathrm{C}$ down to $750^{\circ} \mathrm{C}$ yields a decrease of the sintering rate by an order of magnitude (from $K_{s} \simeq 2 \times 10^{-3} \mathrm{~min}^{-1}$ down to $K_{s} \simeq 2 \times 10^{-4}$ $\min ^{-1}$ ) [42], which would cause a decrease of the sintering factor from $a=0.182$ to $a=0.0776$ in the looping-calcination time period of our tests $\left(t_{s}=5 \mathrm{~min}\right)$. In our experimental work, we performed further TGA multicyclic tests by reducing the calcination temperature down to $750^{\circ} \mathrm{C}$. As expected, the multicyclic $\mathrm{CaO}$ conversion was observed to be enhanced and marked reactivation was observed even for the non preground thermally pretreated sorbent (see Fig. 5).

\section{A. Analysis of multicyclic $\mathrm{CaO}$ conversion data}

Equation 2 has been well fitted [46] to multicyclic conversion data reported elsewhere on pretreated limestones under a wide variety of conditions such as temperature and duration of the pretreatment, presence of additives/impurities in the sorbent, presence of $\mathrm{H}_{2} \mathrm{O}$ and $\mathrm{CO}_{2}$, pre-grinding, and for diverse looping carbonation conditions [21-23]. It must be noted however that multicyclic conversion data reported in the literature usually refers to the overall conversion measured at the end of the carbonation stage thus including both fast and diffusive carbonation. Yet, only conversion in the fast phase would be proportional to the surface area available in each cycle. Furthermore, Eq. 2 would not be in principle applicable to long series of carbonation/calcination cycles. In order to account for the observed behavior at large $N$ indicating that conversion tends to a residual value the model needs additional elaboration (see [46] for more details). For a large number of cycles, sintering/regeneration factors should be corrected by a factor $\left(S_{i}-S_{r}\right) /\left(S_{0}-S_{r}\right)$ 
that makes them to decrease gradually as the residual surface area $S_{r}$ is approached and the sintering/regeneration mechanisms are attenuated.

Figure 8 shows data on $X_{K N} / X_{K 0}$ derived from the tests presented in this manuscript as a function of the cycle number, which are well fitted by Eq. 2 using $a=0.182\left(T_{\text {calc }}=850^{\circ} \mathrm{C}\right)$ and $a=0.0776\left(T_{\text {calc }}=750^{\circ} \mathrm{C}\right)$ as previously derived from independent measurements. The best fits are specially good in the case of sorbents showing marked reactivation whereas it is otherwise for nonpretreated sorbents. The latter suggests that the German-Munir model for the sintering of nascent $\mathrm{CaO}$ (Eq. 1) fails to describe the sintering of the active $\mathrm{CaO}$ skeleton of nonpretreated sorbents as the number of cycles is built up. On the other hand, in the case of pretreated sorbents exhibiting marked reactivation, the active $\mathrm{CaO}$ skeleton is newly generated in each cycle and therefore its sintering during the 5 minutes short calcination period can be well described by the German-Munir model. Values from the best fitting parameters $b / a$ and $\beta$ are plotted in Fig. 9, where also the values derived from the best fits [46] to experimental data reported elsewhere [21-23] are also plotted. As can be seen, the correlation between these parameters adjusts to a universal trend in spite of the wide variety of experimental conditions used in the different works. The regeneration exponent $\beta$ follows a logarithmic decay with the ratio $b / a$ indicating that a significant surface area regeneration (large $b / a$ ), as it is the case of harshly pretreated sorbents, yields in the next cycle a marked increase of fast carbonation. This implies a steep reduction of diffusive carbonation and thus a decrease of surface area regeneration with the cycle number ( $\beta$ small). If, on the other hand, the initial surface area is relatively large diffusive carbonation and thus surface regeneration are negligible (small $b / a)$. As this skeleton becomes progressively sintered in subsequent cycles diffusive carbonation and surface area regeneration are increased ( $\beta$ large) even though not by an appreciable amount to affect conversion significantly if $b<<a$ as for nonpretreated sorbents. In the intermediate case (mildly pretreated sorbents or harshly pretreated sorbents but afterwards subjected to harsh looping-calcination conditions) surface area loss and regeneration are equilibrated $(b / a \simeq 1$ and $\beta \simeq 1)$, which leads to a stable although small multicyclic conversion.

From the analysis of data reported in this and previous works it seems clear that sorbent reactivation by heat pretreatment only becomes apparent under certain looping-carbonation conditions that favor solid-state diffusion (high $\mathrm{CO}_{2}$ vol\% and prolonged carbonation times) and mild looping-calcination conditions (low $\mathrm{CO}_{2}$ vol\% and calcination temperatures below 
$850^{\circ} \mathrm{C}$ ). The feasibility of this technique is thus compromised by the otherwise short carbonation times, low $\mathrm{CO}_{2}$ vol\% during carbonation and harsh calcination conditions to be found in practice. Recent studies point towards the possibility of reactivation under practical looping carbonation/calcination conditions using diverse methods but also implying the enhancement of diffusive carbonation. The evolution of $\mathrm{CaO}$ conversion would be strongly affected whenever solid-state diffusive carbonation, which is a crystal structure sensitive property, is relevant. For example, $\mathrm{CaO} /$ mayenite polycrystalline composites are seen to exhibit reactivation similarly to pretreated limestones [47-51] even under severe calcination conditions [51]. As well known, solid-state diffusion is enhanced in polycrystalline materials as compared to pure crystals because of the accelerated diffusion along the grain boundaries [52]. It might thus be argued that diffusion of $\mathrm{CO}_{2}$ in these composites is enhanced across the interface between $\mathrm{CaO}$ and mayenite crystallites, which would give rise to reactivation. In agreement with this argument, carbonation curves obtained from TGA tests are characterized by an enhanced diffusion controlled carbonation phase (see Fig. 3 in [51]). A promising technique of practical interest for sorbent reactivation is the introduction of steam during looping carbonation, which reduces the diffusion resistance thus promoting diffusive carbonation [18, 40, 53]. A feasible new CaL concept to reactivate low-cost natural limestone based also on the intensification of diffusive carbonation consists of the introduction of a recarbonation stage in between the carbonation and calcination stages of the CaL process [54]. According to this novel concept, the partially carbonated $\mathrm{CaO}$ particles would be circulated before calcination to a recarbonator reactor where further carbonation by means of $\mathrm{CO}_{2}$ diffusion would be promoted by using pure $\mathrm{CO}_{2}$ (available from the calciner) and a relatively high temperature (around $800^{\circ} \mathrm{C}$ ). This leads to a $\mathrm{CaO}$ skeleton with enhanced activity after regeneration.

\section{CONCLUSION}

Experimental results presented in this work as well as others reported in the literature carried out in a wide variety of pretreatment and carbonation/calcination conditions show that the multicyclic $\mathrm{CaO}$ conversion is ruled by a balance between the surface area loss due to sintering in the calcination stage of the cycle and surface area regeneration caused by solid-state diffusion carbonation. $\mathrm{CaO}$ reactivation during carbonation/calcination cycles 
is promoted by the enhancement of solid-state diffusion controlled carbonation, which may be achieved by heat pretreatment. The relative gain of surface area with the cycle number can be modeled by a power law $\Delta S_{i}^{\prime} / S_{i}=b /(1+i)^{q}$, where $b$ is a so-called sintering factor and the sign of the exponent $q$ depends on whether enhanced diffusive carbonation gives rise to surface area regeneration $(q>0)$ or not $(q<0)$. Typically, the former would be the case of sorbents showing reactivation since diffusive carbonation fades away as the cycle number is increased whereas in the latter case the progressive reduction of surface area due to sintering promotes diffusive carbonation as the cycle number is increased. In the initial carbonation/calcination cycles, the reduction of surface area due to sintering is well described by the German-Munir model $\Delta S_{i} / S_{i}^{\prime}=a$. The evolution of conversion with the cycle number can be thus described by the analytical equation $(1-a)^{N}(1+b)^{N^{\beta}}\left(\beta=e^{-q}\right)$ which fits well to experimental data on conversion reported elsewhere and in the present work. The regeneration exponent $\beta$ is seen to conform to a universal logarithmic decay with the ratio of the regeneration to sintering factors $b / a$ indicating that a large increase of surface area in the first cycle $(b / a>>1)$ leads to a marked reactivation in the following few cycles but unsustainable beyond that. Long-termed reactivation would be on the other hand attained for values of $b / a$ slightly above unity, which is helped by grinding prior to thermal pretreatment. The use of this equation would allow foreseeing the critical conditions necessary for sorbent reactivation $(b / a>1$ and $\beta<1)$. According to physisorption analysis a steady reactivation is correlated to a shift in the distribution of pores to the mesopore region. On the other hand, we have seen that carbonation by solid-state diffusion is almost completely precluded in the case of $\mathrm{CaO}$ derived from a limestone preheated in $\mathrm{CO}_{2}$, which however leads to a great increase of the carbonation rate in the kinetically-controlled phase. Since solid-state diffusivity is a structure sensitive property, a detailed study on how the crystal lattice is affected by thermal stresses during heat treatment and grinding should be carried out to shed further light on the physical mechanism determining the effect of pretreatment on the multicyclic $\mathrm{CaO}$ conversion.

[1] J. Blamey, E. J. Anthony, J. Wang, and P. S. Fennell, "The calcium looping cycle for largescale $\mathrm{CO}_{2}$ capture," Prog. Energ. Combust. Sci., vol. 36, no. 2, pp. 260-279, 2010. 
[2] M. C. Romano, "Modeling the carbonator of a Ca-looping process for $\mathrm{CO}_{2}$ capture from power plant flue gas," Chemical Engineering Science, vol. 69, pp. 257 - 269, 2012.

[3] A. Sanchez-Biezma, J. Ballesteros, L. Diaz, E. de Zarraga, F. Alvarez, J. Lopez, B. Arias, G. Grasa, and J. Abanades, "Postcombustion $\mathrm{CO}_{2}$ capture with $\mathrm{CaO}$. status of the technology and next steps towards large scale demonstration," Energy Procedia, vol. 4, no. 0, pp. 852 $859,2011$.

[4] M. C. Romano, E. N. Cassotti, P. Chiesa, J. Meyerb, and J. Mastin, "Application of the sorption enhanced-steam reforming process in combined cycle-based power plants," Energy Procedia, vol. 4, pp. 1125-1132, 2011.

[5] J. M. Criado, M. Macias, and A. Macias-Machin, "Analysis of the system $\mathrm{CaO}-\mathrm{CO}_{2}-\mathrm{H}_{2} \mathrm{O}$ for storage of solar thermal energy," Solar Energy, vol. 49, pp. 83-86, 1992.

[6] S. E. Edwards and V. Materic, "Calcium looping in solar power generation plants," Solar Energy, vol. 86, no. 9, pp. 2494 - 2503, 2012.

[7] K. Johnsen, H. J. Ryu, J. R. Grace, and C. J. Lim, "Sorption-enhanced steam reforming of methane in a fluidized bed reactor with dolomite as $\mathrm{CO}_{2}$-acceptor," Chem. Eng. Sci., vol. 61, no. 4, pp. 1195-1202, 2006.

[8] S. Chen, W. Xiang, D. Wang, and Z. Xue, "Incorporating IGCC and CaO sorption - enhanced process for power generation with $\mathrm{CO}_{2}$ capture," Applied Energy, vol. 95, pp. 285 - 294, 2012.

[9] A. Martinez, Y. Lara, P. Lisbona, and L. M. Romeo, "Energy penalty reduction in the calcium looping cycle," International Journal of Greenhouse Gas Control, vol. 7, pp. 74- 81, 2012.

[10] R. Barker, "Reversibility of the reaction $\mathrm{CaCO}_{3}=\mathrm{CaO}+\mathrm{CO}_{2}$," J. Appl. Chem. Biotechnol., vol. 23 , pp. $733-742,1973$.

[11] G. Grasa, R. Murillo, M. Alonso, and J. C. Abanades, "Application of the random pore model to the carbonation cyclic reaction," AIChE J., vol. 55, no. 5, pp. 1246-1255, 2009.

[12] S. K. Bhatia and D. D. Perlmutter, "Effect of the product layer on the kinetics of the co2-lime reaction," AIChE Journal, vol. 29, no. 1, pp. 79-86, 1983.

[13] Z. Sun, S. Luo, P. Qi, and L.-S. Fan, "Ionic diffusion through calcite $\left(\mathrm{CaCO}_{3}\right)$ layer during the reaction of cao and $\left\{\mathrm{CO}_{2}\right\}$," Chemical Engineering Science, vol. 81, pp. $164-168,2012$.

[14] N. Rodriguez, M. Alonso, J. C. Abanades, A. Charitos, C. Hawthorne, G. Scheffknecht, D. Y. Lu, and E. J. Anthony, "Comparison of experimental results from three dual fluidized bed test facilities capturing $\mathrm{CO}_{2}$ with CaO," Energy Procedia, vol. 4, pp. 393 - 401, 2011. 
[15] B. Arias, J. C. Abanades, and G. S. Grasa, "An analysis of the effect of carbonation conditions on $\mathrm{CaO}$ deactivation curves," Chem. Eng. J., vol. 167, no. 1, pp. 255-261, 2011.

[16] W. Liu, H. An, C. Qin, J. Yin, G. Wang, B. Feng, and M. Xu, "Performance enhancement of calcium oxide sorbents for cyclic $\mathrm{CO}_{2}$ capturea review," Energy $\&$ Fuels, vol. 26, no. 5, pp. 2751-2767, 2012.

[17] J. M. Valverde, "Ca-based synthetic materials with enhanced $\mathrm{CO}_{2}$ capture efficiency," J. Mater. Chem. A., vol. 1, p. 447 468, 2013.

[18] F. Donat, N. H. Florin, E. J. Anthony, and P. S. Fennell, "Influence of high-temperature steam on the reactivity of $\mathrm{CaO}$ sorbent for $\mathrm{CO}_{2}$ capture," Environmental Science \& Technology, vol. 46 , pp. $1262-1269,2012$.

[19] S. Champagne, D. Y. Lu, A. Macchi, R. T. Symonds, and E. J. Anthony, "Influence of steam injection during calcination on the reactivity of CaO-based sorbent for carbon capture," Industrial \& Engineering Chemistry Research, vol. 52, no. 6, pp. 2241-2246, 2013.

[20] A. I. Lysikov, A. N. Salanov, and A. G. Okunev, "Change of $\mathrm{CO}_{2}$ carrying capacity of $\mathrm{CaO}$ in isothermal recarbonation-decomposition cycles," Ind. Eng. Chem. Res., vol. 46, pp. 4633 4638, 2007.

[21] V. Manovic and E. J. Anthony, "Thermal activation of CaO-based sorbent and self-reactivation during $\mathrm{CO}_{2}$ capture looping cycles," Environ. Sci. Technol., vol. 42, pp. 4170-4174, 2008.

[22] V. Manovic, E. J. Anthony, G. Grasa, and J. C. Abanades, " $\mathrm{CO}_{2}$ looping cycle performance of a high-purity limestone after thermal activation/doping," Energy $\&$ Fuels, vol. 22, p. 3258 $3264,2008$.

[23] V. Manovic, E. J. Anthony, and D. Loncarevic, " $\mathrm{CO}_{2}$ looping cycles with cao-based sorbent pretreated in at high temperature," Chemical Engineering Science, vol. 64, no. 14, pp. 3236 $3245,2009$.

[24] K. O. Albrecht, K. S. Wagenbach, J. A. Satrio, B. H. Shanks, and T. D. Wheelock, "Development of a CaO-based $\mathrm{CO}_{2}$ sorbent with improved cyclic stability," Ind. Eng. Chem. Res., vol. 47, p. $78417848,2008$.

[25] N. H. Florin and A. T. Harris, "Reactivity of cao derived from nano-sized $\mathrm{CaCO}_{3}$ particles through multiple $\mathrm{CO}_{2}$ capture-and-release cycles," Chemical Engineering Science, vol. 64, no. 2, pp. $187-191,2009$. 
[26] Y. Chen, J. Yang, R. N. Dave, and R. Pfeffer, "Granulation of cohesive geldart group c powders in a mini-glatt fluidized bed by pre-coating with nanoparticles," Powder Tech., vol. 191, pp. $206-217,2009$.

[27] V. Manovic, E. J. Anthony, and D. Loncarevic, "Improving the stability of a CaO-based sorbent for $\mathrm{CO}_{2}$ by thermal pretreatment," Ind. Eng. Chem. Res., vol. 50, p. 69336942 , 2011 .

[28] J. M. Valverde, P. E. Sanchez-Jimenez, A. Perejon, and L. A. Perez-Maqueda, "Role of loopingcalcination conditions on self-reactivation of thermally pretreated $\mathrm{CO}_{2}$ sorbents based on CaO," Energy \& Fuels, vol. 27, p. 3373 3384, 2013.

[29] M. Alonso, M. Lorenzo, B. Gonzalez, and J. C. Abanades, "Precalcination of $\mathrm{CaCO}_{3}$ as a method to stabilize $\mathrm{CaO}$ performance for $\mathrm{CO}_{2}$ capture from combustion gases," Energy $\mathscr{E}$ Fuels, vol. 25, no. 11, pp. 5521-5527, 2011.

[30] G. Kaupp, "Mechanochemistry: the varied applications of mechanical bond-breaking," CrystEngComm, vol. 11, pp. 388-403, 2009.

[31] G. S. Grasa and J. C. Abanades, " $\mathrm{CO}_{2}$ capture capacity of $\mathrm{CaO}$ in long series of carbonation/calcination cycles," Ind. Eng. Chem. Res., vol. 45, no. 26, pp. 8846-8851, 2006.

[32] B. Arias, J. C. Abanades, and E. J. Anthony, "Model for self-reactivation of highly sintered $\mathrm{CaO}$ particles during $\mathrm{CO}_{2}$ capture looping cycles," Energy Fuels, vol. 25, pp. 1926-1930, 2011.

[33] H. S. S. Z. Chen, M. Portillo, C. J. Lim, J. R. Grace, and E. J. Anthony, "Long-term calcination/carbonation cycling and thermal pretreatment for $\mathrm{CO}_{2}$ capture by limestone and dolomite," Energy 83 Fuels, vol. 23, p. 1437 1444, 2009.

[34] D. R. Glasson, "Reactivity of lime and related oxides. xvi. sintering of lime," J. Appl. Chem., vol. 17 , p. $9196,1967$.

[35] J. C. Abanades and D. Alvarez, "Conversion limits in the reaction of $\mathrm{CO}_{2}$ with lime," Energy E Fuels, vol. 17, pp. 308 - 315, 2003.

[36] P. Carrott and K. Sing, "Assessment of microporosity," in Characterization of Porous Solids Proceedings of the IUPAC Symposium (COPS I), Bad Soden a. Ts. (K. S. K.K. Unger, J. Rouquerol and H. Kral, eds.), vol. 39 of Studies in Surface Science and Catalysis, pp. 77 - 87, Elsevier, 1988.

[37] D. Lozano-Castell, D. Cazorla-Amors, and A. Linares-Solano, "Usefulness of $\{\mathrm{CO} 2\}$ adsorption at $273 \mathrm{k}$ for the characterization of porous carbons," Carbon, vol. 42, no. 7, pp. 1233 - 
$1242,2004$.

[38] H. Schmalzried, One- and Two-Dimensional Defects in Crystals, pp. 43-60. Wiley-VCH Verlag GmbH, 2007.

[39] M. Liu and B. Evans, "Dislocation recovery kinetics in single-crystal calcite," Journal of Geophysical Research: Solid Earth, vol. 102, no. B11, pp. 24801-24809, 1997.

[40] A. Kronenberg, R. Yund, and B. Giletti, "Carbon and oxygen diffusion in calcite: Effects of Mn content and PH2O," Physics and Chemistry of Minerals, vol. 11, no. 3, pp. 101-112, 1984.

[41] T. F. Anderson, "Self-diffusion of carbon and oxygen in calcite by isotope exchange with carbon dioxide," Journal of Geophysical Research, vol. 74, no. 15, pp. 3918-3932, 1969.

[42] R. H. Borgwardt, "Sintering of nascent calcium oxide," Chem. Eng. Sci., vol. 44, no. 1, pp. 5360, 1989.

[43] R. H. Borgwardt, "Calcium oxide sintering in atmospheres containing water and carbon dioxide," Industrial \& Engineering Chemistry Research, vol. 28, no. 4, pp. 493 - 500, 1989.

[44] A. B. Fuertes, D. Alvarez, F. Rubiera, J. J. Pis, and G. Marban, "Surface area and pore size changes during sintering of calcium oxide particles," Chemical Engineering Communications, vol. 109, no. 1, pp. $73-88,1991$.

[45] B. Stanmore and P. Gilot, "Review - calcination and carbonation of limestone during thermal cycling for $\mathrm{CO}_{2}$ sequestration," Fuel Processing Technology, vol. 86, no. 16, pp. 1707 - 1743, 2005 .

[46] J. M. Valverde, "A model on the CaO multicyclic conversion in the ca-looping process," Chemical Engineering Journal, vol. 228, p. 1195 1206, 2013.

[47] Z. shan Li, N. sheng Cai, Y. yu Huang, and H. jin Han, "Synthesis, experimental studies, and analysis of a new calcium-based carbon dioxide absorbent," Energy $\&$ Fuels, vol. 19, pp. 1447 $-1452,2005$.

[48] C. S. Martavaltzi and A. A. Lemonidou, "Parametric study of the cao-ca12al14o33 synthesis with respect to high $\mathrm{CO}_{2}$ sorption capacity and stability on multicycle operation," Ind. Eng. Chem. Res., vol. 47, p. 9537 9543, 2008.

[49] R. Pacciani, C. R. Muller, J. F. Davidson, J. S. Dennis, and A. N. Hayhurst, "Synthetic ca-based solid sorbents suitable for capturing $\mathrm{CO}_{2}$ in a fluidized bed," Can. J. Chem. Eng., vol. 86 , p. 356 366, 2008 . 
[50] R. Pacciani, C. R. Mller, J. F. Davidson, J. S. Dennis, and A. N. Hayhurst, "How does the concentration of co2 affect its uptake by a synthetic ca-based solid sorbent?," AIChE Journal, vol. 54, no. 12, pp. 3308-3311, 2008.

[51] S. Stendardo, L. Andersen, and C. Herce, "Self-activation and effect of regeneration conditions in $\mathrm{CO}_{2}$ carbonate looping with $\mathrm{CaO} \mathrm{Ca}_{12} \mathrm{Al}_{14} \mathrm{O}_{33}$ sorbent," Chemical Engineering Journal, vol. 220 , pp. $383-394,2013$.

[52] H. S. Levine and C. J. MacCallum, "Grain boundary and lattice diffusion in polycrystalline bodies," Journal of Applied Physics, vol. 31, no. 3, pp. 595-599, 1960.

[53] V. Manovic and E. J. Anthony, "Carbonation of CaO-based sorbents enhanced by steam addition," Ind. Eng. Chem. Res., vol. 49, p. 9105 9110, 2010.

[54] B. Arias, G. S. Grasa, M. Alonso, and J. C. Abanades, "Post - combustion calcium looping process with a highly stable sorbent activity by recarbonation," Energy Environ. Sci., vol. 5, pp. $7353-7359,2012$. 

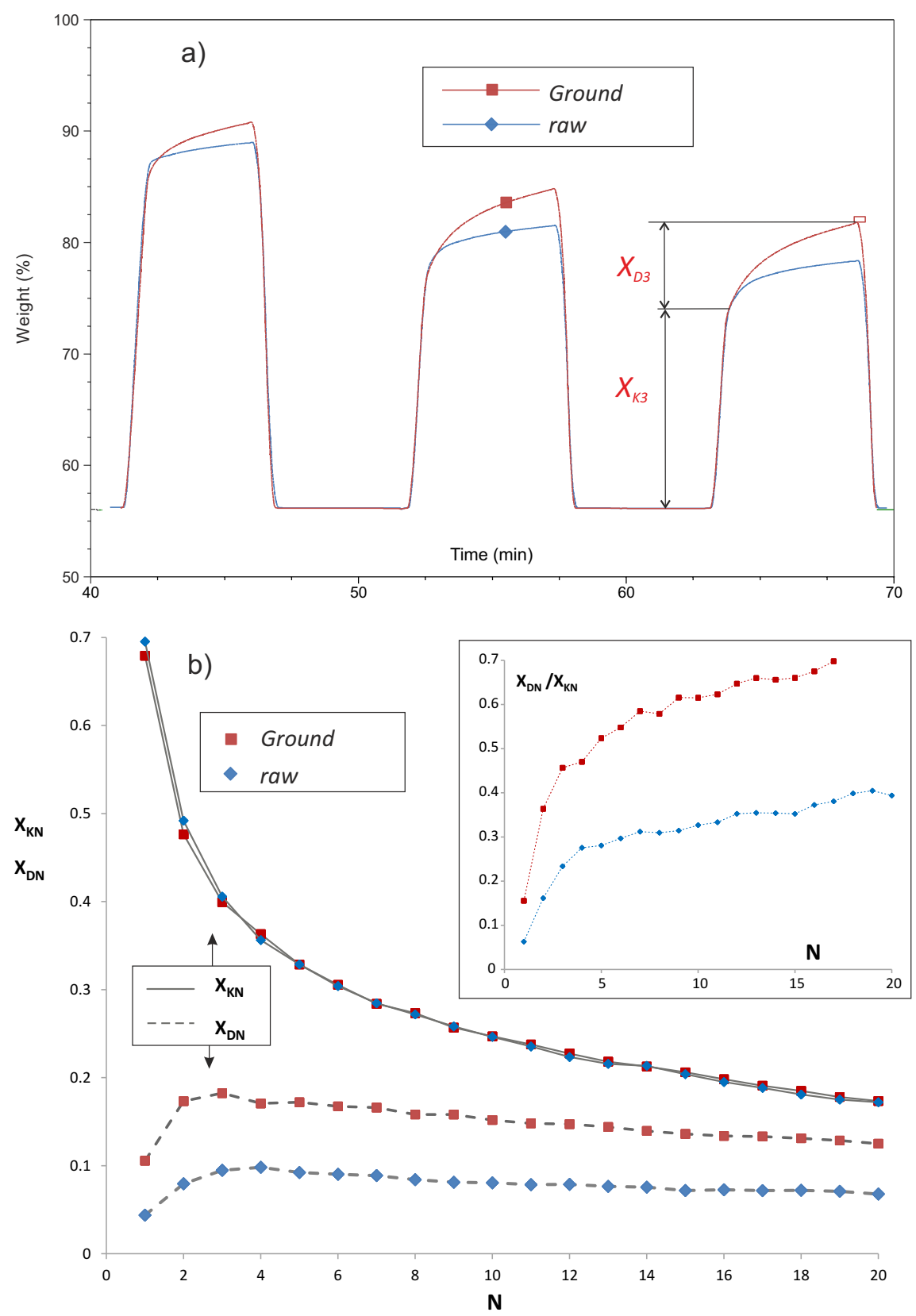

FIG. 1. a) Sorbent weight $\%$ as registered during TGA tests in the first 3 carbonation/calcination cycles for raw and preground limestone samples. Conversion in the fast kinetically-driven and solid-state diffusion controlled phases for the 3rd cycle of the preground sorbent are indicated b) Conversion in the fast carbonation phase $\left(X_{K N}\right)$ and in the slow phase $\left(X_{D N}\right)$ as a function of the cycle number for both samples. The inset of b) shows the ratio $X_{D N} / X_{K N}$ as a function of the cycle number for both samples. 

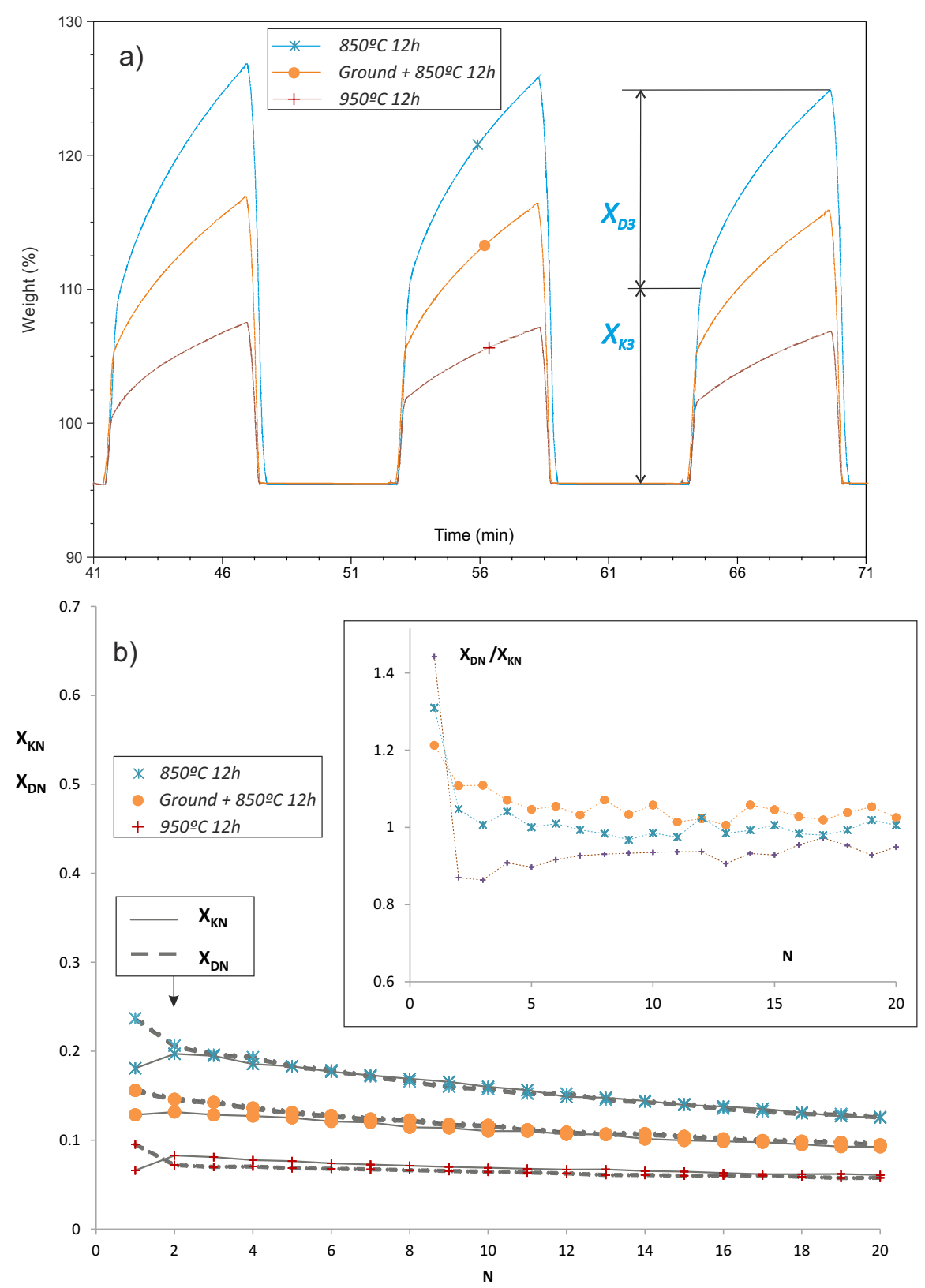

FIG. 2. a) Sorbent weight $\%$ as registered during TGA tests in the first 3 carbonation/calcination cycles for samples of thermally pretreated limestone (in dry air) as indicated. Conversion in the fast kinetically-driven and solid-state diffusion controlled phases for the 3rd cycle of the sorbent pretreated at $850^{\circ}$ for $12 \mathrm{~h}$ are indicated. b) Conversion in the fast carbonation phase $\left(X_{K N}\right)$ and in the slow phase $\left(X_{D N}\right)$ as a function of the cycle number. The inset of b) shows the ratio $X_{D N} / X_{K N}$ as a function of the cycle number. 


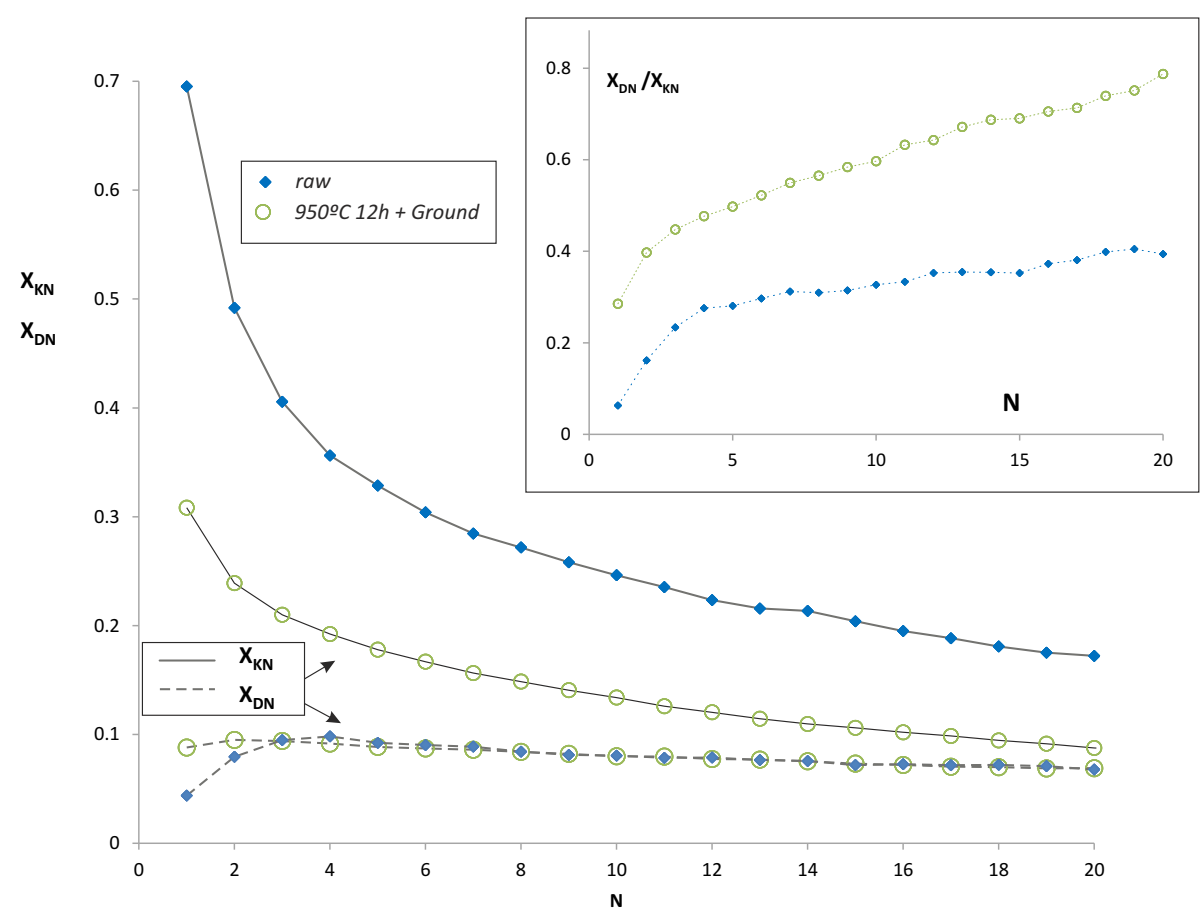

FIG. 3. Conversion in the kinetically-driven fast carbonation phase $\left(X_{K N}\right)$ and in the slow phase controlled by solid-state diffusion $\left(X_{D N}\right)$ as a function of the cycle number for samples of raw sorbent and sorbent ground after thermal pretreatment $\left(950^{\circ} \mathrm{C}, 12 \mathrm{~h}\right.$ in dry air). The inset of shows the ratio $X_{D N} / X_{K N}$ as a function of the cycle number. 

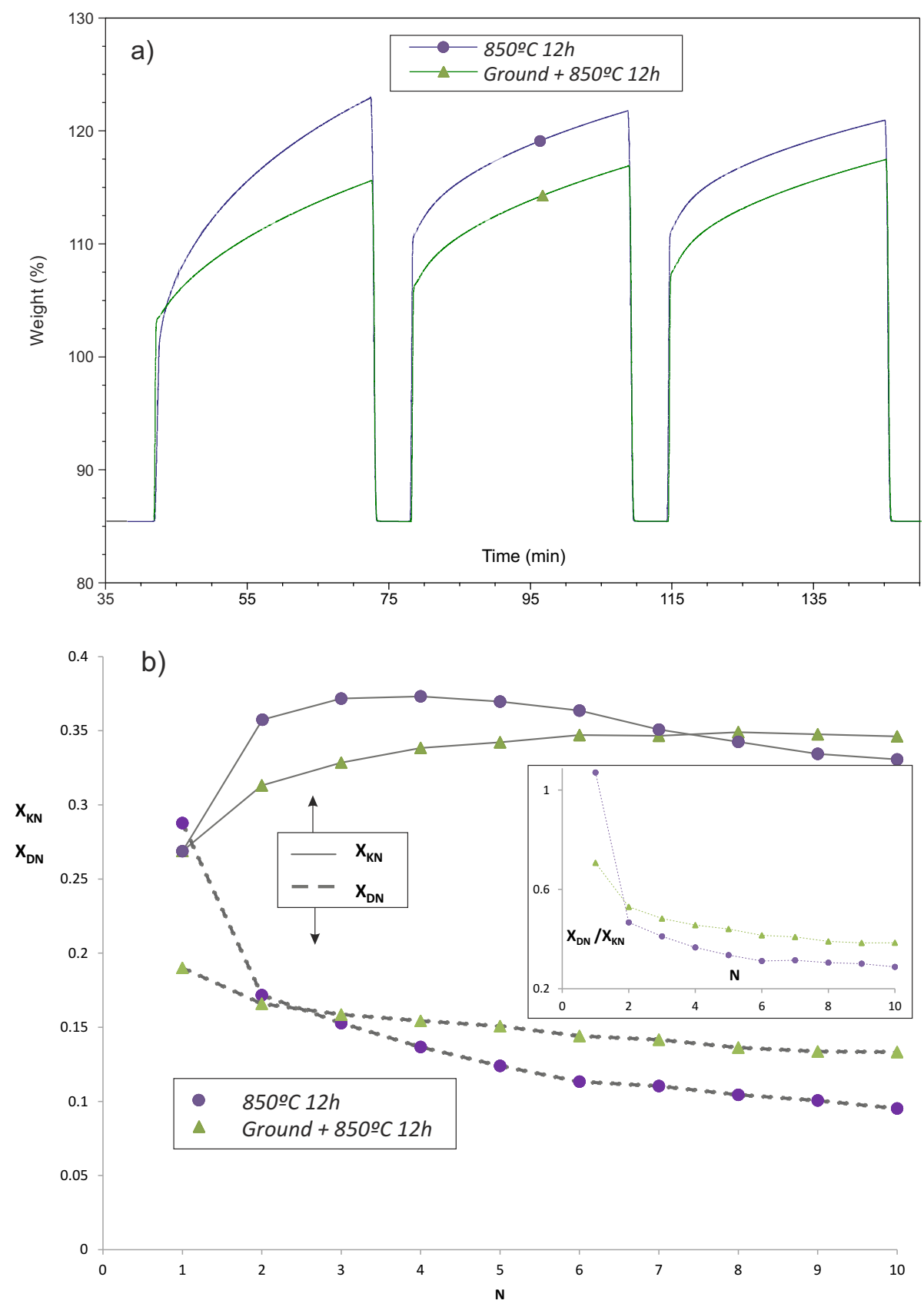

FIG. 4. a) Sorbent weight $\%$ as registered during TGA tests in the first 3 carbonation/calcination cycles for samples of thermally pretreated limestone (in dry air) as indicated. b) Conversion in the fast carbonation phase $\left(X_{K N}\right)$ and in the slow phase $\left(X_{D N}\right)$ as a function of the cycle number. The inset of b) shows the ratio $X_{D N} / X_{K N}$ as a function of the cycle number. In these tests the $\mathrm{CO}_{2}$ vol\% during carbonation was increased up to $50 \%$ and the carbonation time was prolonged up to $30 \mathrm{~min}$. TGA cycles on these samples were carried out 48 hours after thermal pretreatment being partially carbonated before the TGA tests. 

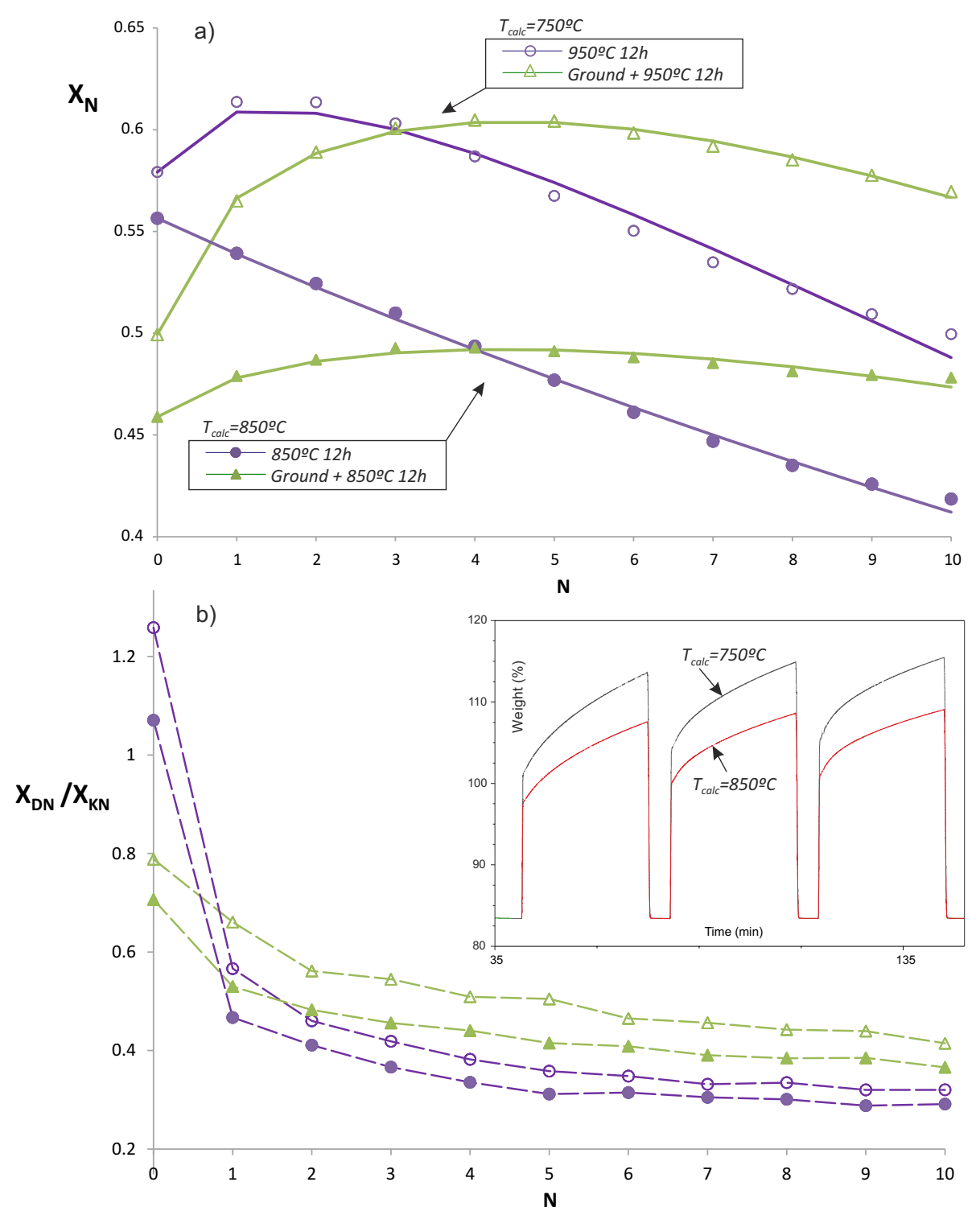

FIG. 5. a) Total Conversion at the end of the carbonation stage $\left(X_{N}=X_{K N}+X_{D N}\right)$ as a function of the cycle number for pretreated limestones (in dry air) as indicated. b) Ratio of conversion in the diffusive phase to conversion in the fast phase. In these tests the $\mathrm{CO}_{2}$ vol\% during carbonation was increased up to $50 \%$ and the carbonation time was prolonged up to $30 \mathrm{~min}$. Calcination was carried out in $N_{2}$ for $5 \mathrm{~min}$ at either $750^{\circ} \mathrm{C}$ or $850^{\circ} \mathrm{C}$ as indicated. The solid lines in a) are drawn from the best fits of Eq. 2 to the data. The dashed lines in b) are a guide to the eyes. The inset of $\mathrm{b}$ ) shows the evolution of the weight $\%$ gain in the first 3 cycles for the preground samples at the different looping-calcination temperatures. 

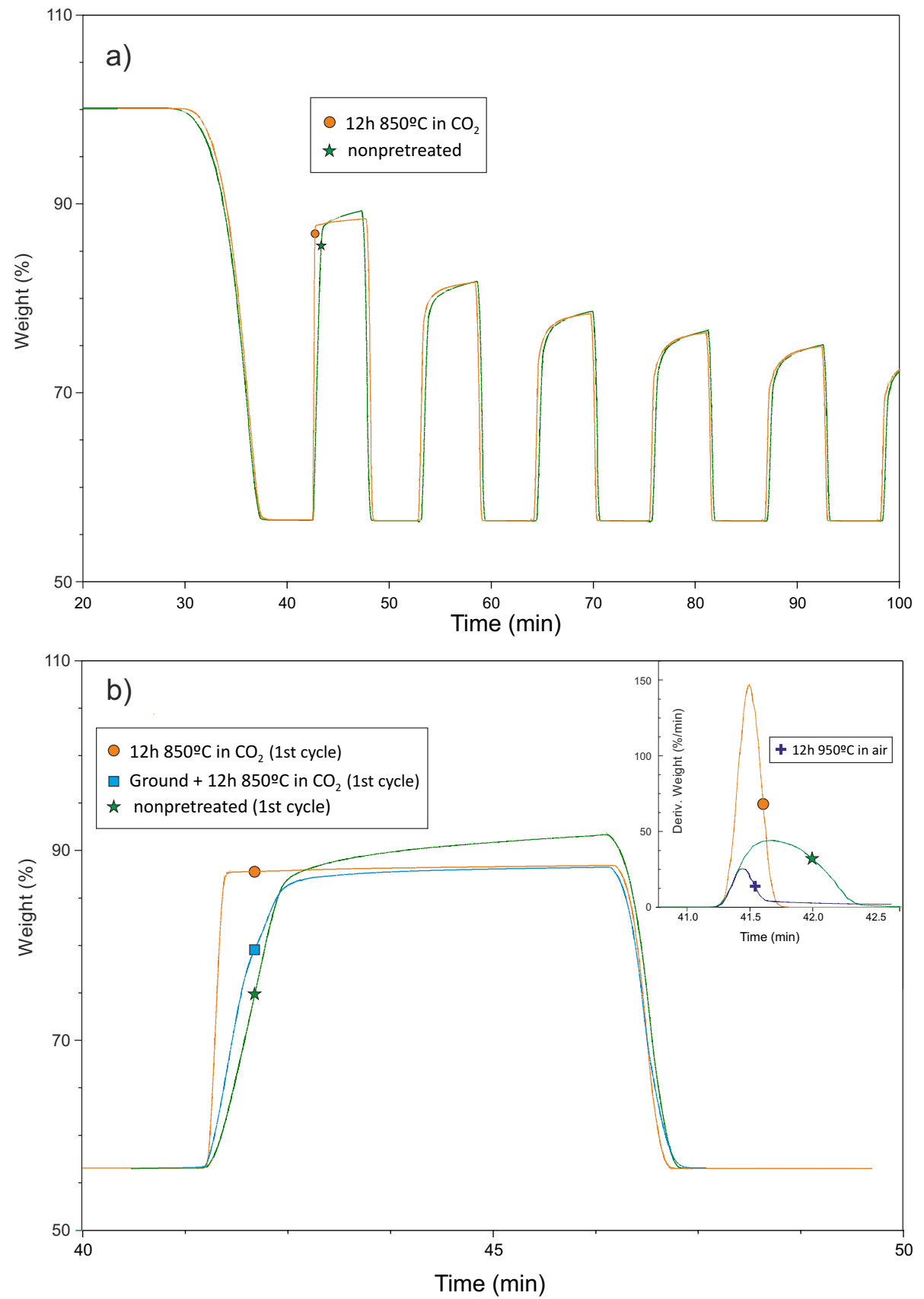

FIG. 6. a) Thermograms obtained from TGA multicyclic tests on samples of raw limestone and limestone preheated for $12 \mathrm{~h}$ at $850^{\circ} \mathrm{C}$ in a pure $\mathrm{CO}_{2}$ atmosphere. b) 1st carbonation/calcination cycle including also the thermogram obtained for a preground sample after which it was preheated for $12 \mathrm{~h}$ at $850^{\circ} \mathrm{C}$ in a pure $\mathrm{CO}_{2}$ atmosphere. The inset shows the weight $\%$ derivative as a function of time in the 1st cycle carbonation (the curve obtained for the limestone preheated in air for 12 $\mathrm{h}$ at $950^{\circ} \mathrm{C}$ is also shown for comparison). 


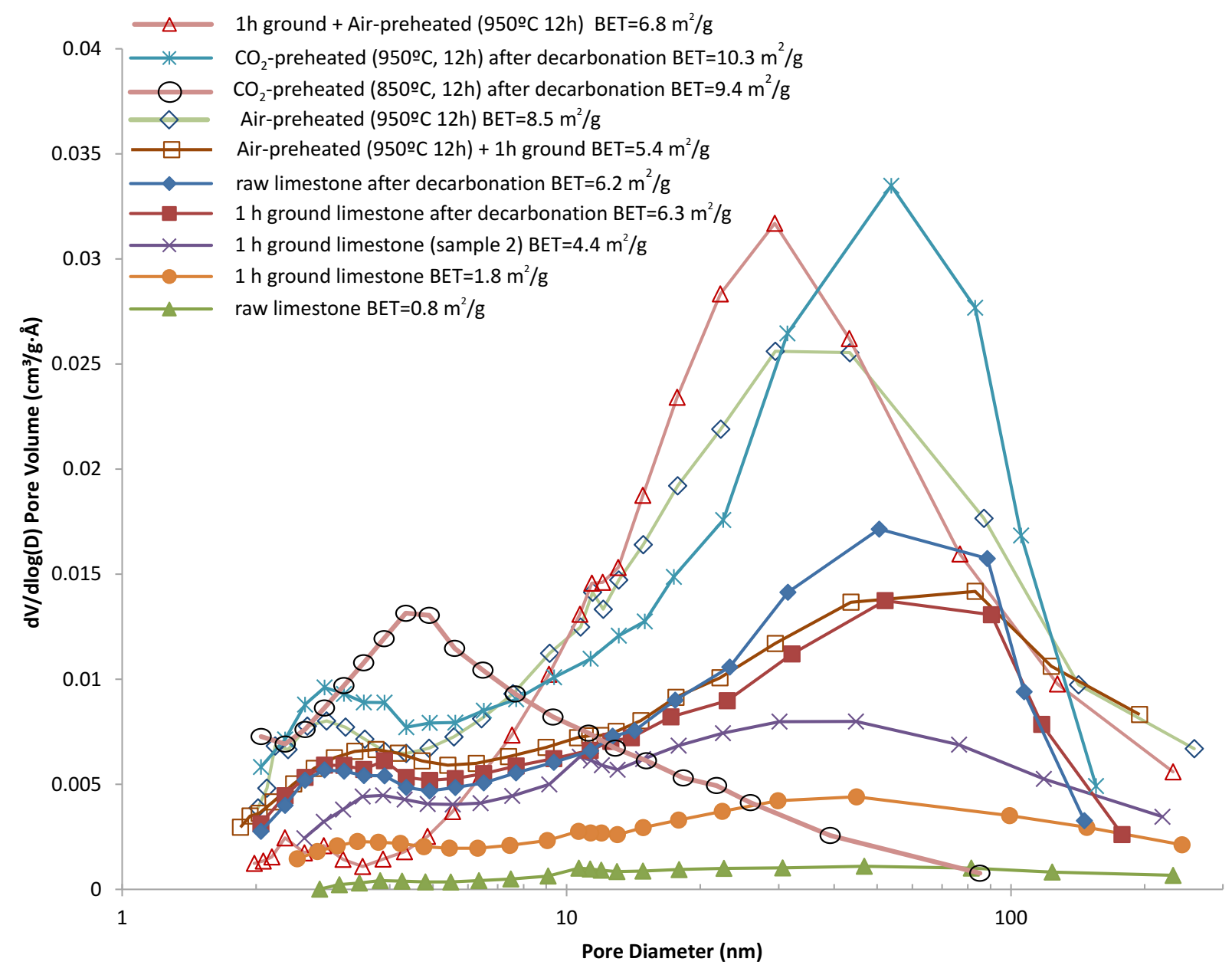

FIG. 7. Pore size distributions of raw and pretreated limestone samples after being subjected to diverse pretreatments and, when indicated, rapid decarbonation $\left(850^{\circ} \mathrm{C}\right.$ for 30 min in air $)$. BET surface area values are given in the inset. 


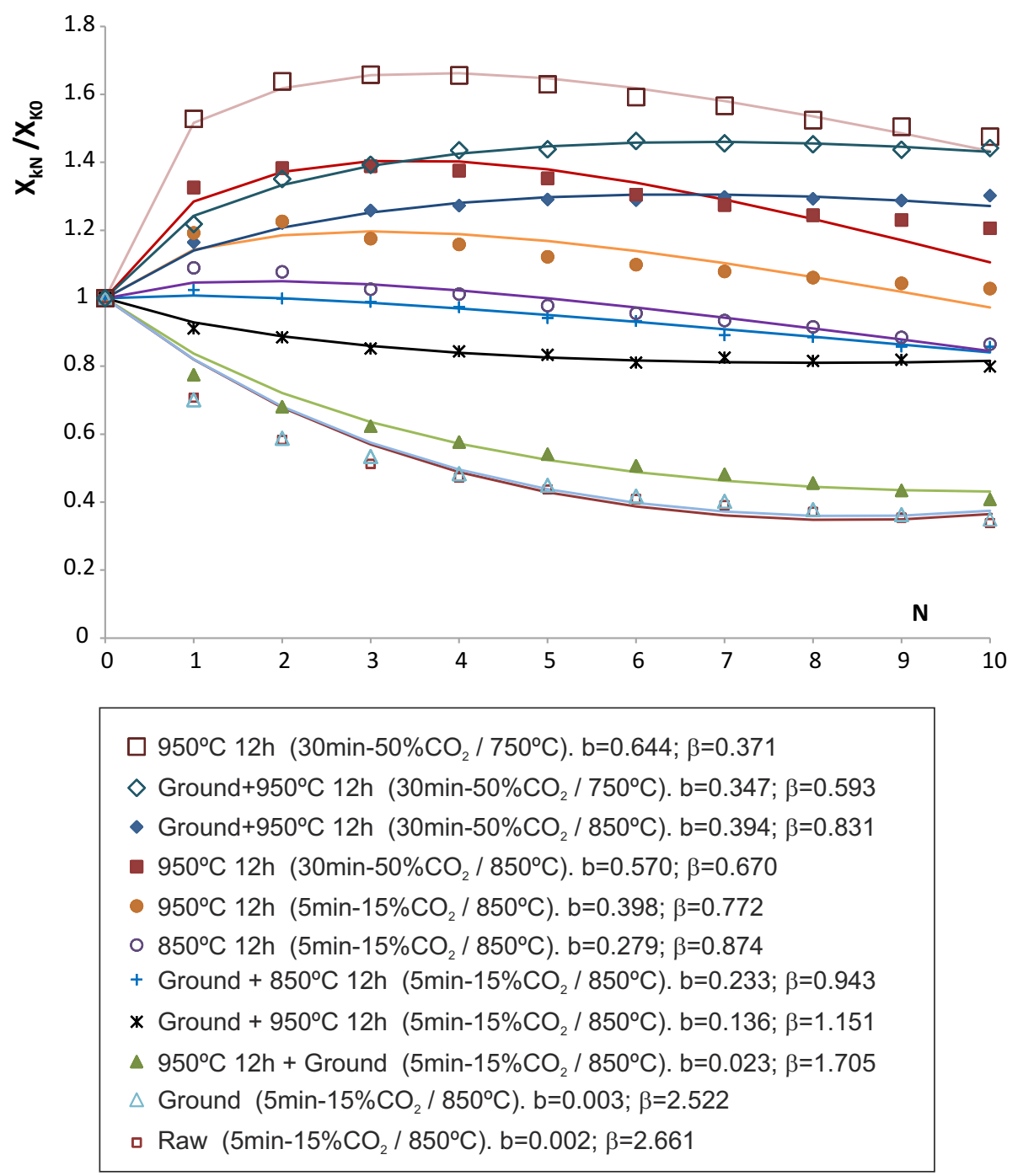

FIG. 8. Conversion at the end of the fast phase $X_{K N}$ (divided by fast conversion in the first cycle $X_{K 0}$ ) vs cycle number for all the sorbents tested in this work and subjected to different pretreatments as indicated. Carbonation/calcination conditions are specified between parentheses. Carbonation in all the tests is carried out at $650^{\circ} \mathrm{C}$ and calcination in a dry air atmosphere. The lines are drawn from the best fits of Eq. 2 to the data using $a=0.184$ for calcination at $850^{\circ} \mathrm{C}$ and $a=0.0776$ for calcination at $750^{\circ} \mathrm{C}$ as derived from independent measurements [42] (best fitting parameters $b$ and $\beta$ are indicated). 


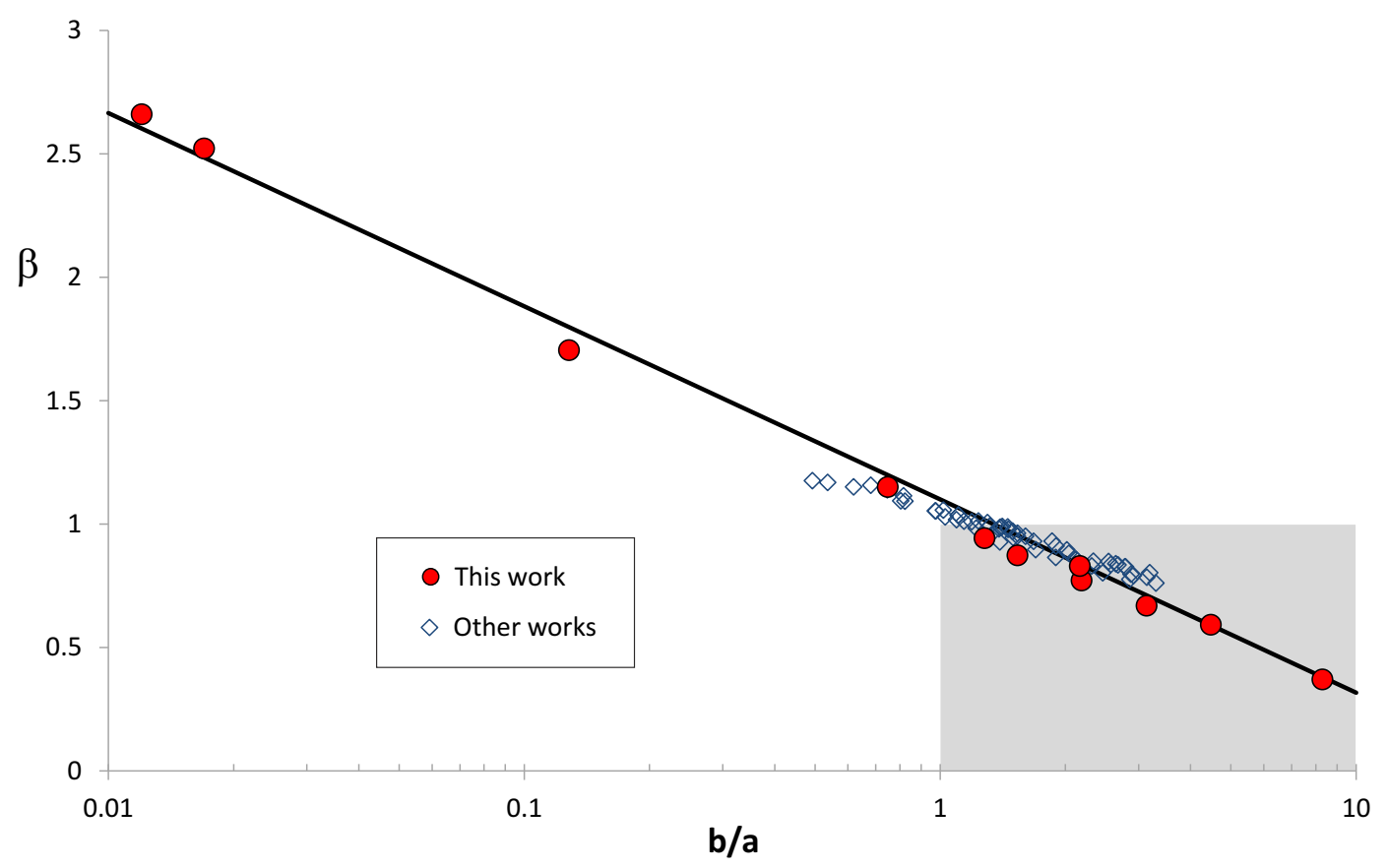

FIG. 9. Regeneration exponent $\beta$ as a function of the ratio of regeneration factor $b$ to sintering factor $a$ obtained from the best fits of Eq. 2 to multicyclic $\mathrm{CaO}$ conversion data for thermally pretreated sorbents under varying conditions reported elsewhere [21-23] (analyzed in ref. [46]) and for the sorbents reported in this work (Fig. 8). The solid line is a plot of the equation $\beta=-0.34 \ln (b / a)+1.1$. The shaded area highlights the reactivation zone $(b>a, \beta<1)$. 